\title{
INTIMACIÓN AL REINTEGRO DE UN TRABAJADOR EFECTUADA VÍA WHATSAPP
}

\author{
NOTIFICATION OF REINSTATEMENT TO THE \\ WORKPLACE THROUGH WHATSAPP
}

\section{CONVOCAÇÃO DE RETORNO AO TRABALHO EFETUADA VIA WHATSAPP}

NICOLÁS RIVADAVIA ${ }^{1}$

RECIBIDO: $16 / 11 / 2020$

APROBADO: 20/11/2020

\begin{abstract}
RESUMEN: el presente trabajo tiene por objeto abordar el análisis de la sentencia dictada por el Tribunal de Apelaciones del Trabajo de $1^{\circ}$ Turno $N^{\circ} 222 / 2020$. Puntualmente, se analizará lo resuelto por el Tribunal sobre la intimación efectuada por el empleador vía WhatsApp a un trabajador que se había ausentado de su puesto de trabajo sin aviso.
\end{abstract}

PALABRAS CLAVE: Abandono, Intimación, Reintegro, WhatsApp

ABSTRACT: this paper has the objective of approaching the analysis of the $1^{\circ}$ Labor Court of Appeal judicial ruling $\mathrm{N}^{\circ} 222 / 2020$. Specifically, it will be analyzed the Court resolution regarding the notification executed by the employer through WhatsApp to an employee that had been absent to the workplace without previous notice.

KEY WORDS: Unjustified absence, Notification, Reinstatement, WhatsApp

RESUMO: o presente trabalho visa abordar a análise do acórdão do Tribunal de Apelações do Trabalho do $1^{\circ}$ Turno $N^{\circ} 222 / 2020$. Precisamente, será analisada a decisão do Tribunal sobre a convocação feita pelo empregador via Whatsapp a um trabalhador que se havia ausentado de seu posto de trabalho sem aviso prévio.

PALAVRAS-CHAVE: Abandono, Convocação, Retorno, WhatsApp

1 Doctor en Derecho egresado de la Facultad de Derecho de la Universidad de Montevideo. Cursando Postgrado en Derecho del Trabajo Aplicado de la Universidad de Montevideo. Abogado Senior en Estudio Hughes \& Hughes. ORCID ID: https://orcid.org/0000-0002-0076-5359. nrivadavia@hughes.com.uy 


\section{Introducción}

La sentencia dictada por el Tribunal de Apelaciones del Trabajo de $1^{\circ}$ Turno $\mathrm{N}^{\circ}$ 222/2020, de fecha 7 de octubre de 2020 (en adelante, la "Sentencia"), desestimó en todos sus términos la demanda planteada por el actor, no haciendo lugar al reclamo de los rubros indemnización por despido indirecto, descanso intermedio, horas extras e incidencias de horas extras en los rubros licencia, salario vacacional y aguinaldo, confirmando in totum lo resuelto en primera instancia por el Juzgado Letrado de Paysandú de $5^{\circ}$ Turno.

Se analizará a lo largo del presente comentario, la intimación efectuada por la empresa al trabajador reclamante, convocándolo a reintegrarse a su puesto de trabajo a través de la aplicación de celular WhatsApp, elemento que fue tomado en cuenta por el Tribunal al momento de pronunciarse sobre el despido indirecto alegado y reclamado por el actor.

Resulta de particular interés a los efectos de este análisis, las consideraciones plasmadas por el Tribunal respecto a la prueba incorporada por el empleador de imágenes de WhatsApp, a efectos de demostrar en el proceso haber cumplido con la carga de intimar el reintegro del trabajador ante su ausencia sin aviso y la configuración del abandono del trabajo.

\section{El caso}

Conforme surge de la Sentencia, el proceso tiene su origen en la pretensión movilizada por el trabajador reclamante quien se desempeñaba como maquinista, en una empresa que gira en el rubro forestación.

En su demanda, el actor reclamó el pago de los rubros descanso intermedio, horas extras, incidencias de horas extras en los rubros licencia, salario vacacional y aguinaldo e indemnización por despido indirecto provocado por supuestos incumplimientos de su empleador. El reclamo de la indemnización por despido se fundó concretamente en el no pago de horas extras, no goce de descanso intermedio y en la modificación en la forma de remuneración acordada (de jornalero a mensual), lo que llevaron a que el trabajador no se presentara más a trabajar.

Al contestar la demanda, la empresa empleadora controvirtió en todos sus términos el reclamo planteado por el actor, y en lo que refiere específicamente al despido indirecto, expresó que no existió ninguno de los incumplimientos alegados.

Asimismo, el empleador alegó haber cumplido con la carga de intimar al trabajador al reintegro a su puesto de trabajo luego de su ausencia sin aviso por algunos días.

Según surge de la Sentencia, el trabajador se desempeñaba como maquinista en una empresa forestal, luego de una interrupción de las tareas por razones climáticas, reanudadas las mismas, el actor no se reintegró a su puesto de trabajo, motivo por el cual, la empresa le aplicó una suspensión por reiteradas faltas injustificadas por el término de 10 días, la cual el trabajador se negó a firmar. 
Una vez cumplida la suspensión, la secretaria de recursos humanos de la empresa, le envió al trabajador un mensaje vía WhatsApp, solicitando su presencia para reintegrarse a las actividades, mensaje que no fue respondido por el actor.

Días después, la empresa le envió un nuevo mensaje vía WhatsApp, el cual tampoco fue respondido por el trabajador. Al día siguiente de haber recibido esta última comunicación, el actor envió un mensaje vía WhatsApp al número desde el cual el empleador le había remitido los mensajes, consultando si el dueño de la empresa estaba en las oficinas, a lo cual la secretaria de recursos humanos respondió que en ese momento no.

El diálogo continuó luego de algunos días, cuando la empresa enviara al actor un audio vía WhatsApp, mediante el cual, nuevamente se lo convocaba a reintegrarse a sus tareas, respondiendo el trabajador que lo haría una vez se le abonara lo que se le debía, dando a entender que se refería a los días que había estado suspendido por faltas injustificadas.

Como prueba de las comunicaciones y de la intimación practicada, la empresa agregó acta de constatación notarial de las conversaciones mantenidas con el trabajador por WhatsApp, demostrativas del interés de esta en continuar la relación de trabajo con el actor.

\section{Intimación al reintegro y abandono del trabajo}

Como lo ha sostenido la doctrina y jurisprudencia laboral, para que se entienda configurado el abandono del puesto de trabajo por parte de un trabajador, el empleador debe intimar el reintegro o aportar prueba que permita concluir la voluntad de rescisión unilateral del contrato de trabajo por parte del empleado, conforme a las reglas de la carga de la prueba del artículo 139 del Código General del Proceso (CGP).

Por tanto, para que el abandono se configure, es necesario que haya por parte del trabajador un incumplimiento voluntario, sin causa que lo justifique, siendo necesario demostrar no sólo que el empleado no trabajó sino que ello obedeció a su intención de disolver el vínculo laboral por parte de este.

Por tal razón, el empleador debe constituir en mora al trabajador ante el incumplimiento de su obligación principal, que es justamente, trabajar o al menos estar a la orden para hacerlo.

Respecto al abandono del trabajo, se ha señalado por parte de nuestra jurisprudencia que:

"Todo acto o conducta que sea revelador del propósito deliberado de dar por terminado el contrato, de que el trabajador por decisión propia no se entiende ya ligado por él...". "Por tanto, para que el abandono pueda considerarse configurado, debe probarse no sólo que el obrero no trabajó, sino que ello obedeció al propósito deliberado de su parte de disolver el vínculo contractual." (Cf. Manuel Alonso Olea, "Derecho del Trabajo", pág.289)..."El patrono debe en ese caso, si entiende que continúa la relación laboral intimar el reintegro al trabajo o aportar prueba suficiente 
que permita concluir en la voluntad de rescisión unilateral del contrato de trabajo por parte del trabajador". ${ }^{2}$ (El destacado me pertenece).

Por su parte, BARBAGELATA afirma que "Doctrinariamente se ha dicho que en los casos de abandono del trabajo, el patrono asume la carga de indagar las causas de la deserción del trabajador; por ello, frente a una ausencia, que exceda lo normal, y siguiendo los usos profesionales, deberá cursar intimación de reincorporarse al puesto o justificar su ausencia. Las prácticas profesionales han adoptado la fórmula del telegrama colacionado". ${ }^{3}$

Por tanto, la jurisprudencia laboral vernácula, ha realizado grandes aportes respecto al abandono del puesto de trabajo y respecto a la carga que recae sobre el empleador de intimar el reintegro o de aportar prueba que acredite que la rescisión del contrato de trabajo fue unilateral del empleado. Comúnmente se ha sostenido que la intimación puede realizarse por telegrama colacionado u otro medio idóneo. Así, se ha expresado que “... El envío de telegrama no resulta en realidad ser la única prueba válida ya que no existe disposición legal alguna que así lo disponga, de donde cuenta el empleador con todos los medios de prueba a su alcance. Lo que sí se requiere, tal como lo postulara la Sala de Primer Turno es que: "para que pueda tener lugar el abandono del trabajo debe constar fehacientemente, ya sea tácita o expresamente, la voluntad del empleado de no continuar la relación, lo que, como ya se expresara puede constatar por cualquier medio de pruebas y no exclusivamente mediante el envío de telegrama colacionado...". (El destacado me pertenece).

En igual sentido, se manifestó el Tribunal de Apelaciones del Trabajo de $1^{\circ}$ Turno "El envío del telegrama constituye una forma de acreditar la existencia de un posible abandono pero no la única. Si impidiésemos la acreditación por otros medios del abandono estaríamos no sólo elevando el envío de telegrama a un requisito de solemnidad, sin disposición que específicamente lo establezca sino también limitando los medios probatorios de que puede disponer el demandado para acreditar el abandono que alega y en definitiva cercenando su derecho de defensa". (El destacado me pertenece). Su homólogo de tercer turno expresó: "Lo que debe acreditar quien esgrime abandono es que la desvinculación operó por la libre voluntad del empleado de no continuar la relación, y para ello puede el empleador interesado recurrir a cualquier medio de prueba". 6 (El destacado me pertenece).

Tradicionalmente, el medio más utilizado por los empleadores para constituir en mora a un trabajador que se ausentaba sin aviso de su lugar de trabajo, era el envío de telegrama colacionado con acuse de recibo intimando el reintegro. En efecto, el telegrama gozaba y goza de cierto grado de certeza que garantiza al empleador la posibilidad de probar haber cumplido con su carga de intimar el reintegro del trabajador en un eventual y futuro litigio.

2 Uruguay, Tribunal de Apelaciones del Trabajo $3^{\circ} \mathrm{T}$, Sentencia $\mathrm{N}^{\circ}$ 101/2007, BJNP. Uruguay, Tribunal de Apelaciones del Trabajo del Trabajo $2^{\circ}$ T, Sentencia SEF - 0013-000092/2014, BJNP. Uruguay, Tribunal de Apelaciones del Trabajo $3^{\circ} \mathrm{T}$, Sentencia $\mathrm{N}^{\circ} 526 / 2010$, BJNP.

3 Barbagelata, H.H.; Derecho del Trabajo, T. I, pág. 341.

4 Uruguay, Juzgado Letrado de Trabajo $14^{\circ}$, Sentencia $N^{\circ} 111$, de fecha 19.10.2004, AJL 2004, Caso 9.

5 Uruguay, Tribunal de Apelaciones del Trabajo de $1^{\circ} \mathrm{T}$, Sentencia N ${ }^{\circ}$ 223, de fecha 25.5.2004, AJL 2004, Caso 10.

6 Uruguay, Tribunal de Apelaciones del Trabajo de 3ํ T, Sentencia SEF - 0014-000035, de fecha 13.5.2015, AJL 2015 Caso 7. 
Sin perjuicio de que el telegrama colacionado continúa siendo un medio idóneo, el avance de la tecnología, su uso masivo y su accesibilidad por parte de la gran mayoría de las personas, ha llevado a que las formas de comunicarse entre los seres humanos haya ido cambiando y evolucionando. De esta forma, hoy día, la tecnología está presente en la vida cotidiana de las personas y la relación laboral no es ajena a ello.

En efecto, en la actualidad existen otros medios que pueden ser considerados idóneos para intimar el reintegro de un empleado a su puesto de trabajo, teniéndose presente que no existe disposición legal que establezca formalidad alguna para dicho acto.

En virtud de lo señalado, la Sentencia viene a dar un paso importante en este tema, asentándose de esta forma lo afirmado con anterioridad. Esto es: la intimación al reintegro a efectos de constituir en mora al trabajador ausente, puede realizarse por diversos medios de los que podrá disponer el empleador en cada caso concreto, distintos al telegrama colacionado.

\section{La intimación vía whatsapp analizada por la sentencia}

En la Sentencia, el Tribunal entendió que si bien el empleador no intimó el reintegro del trabajador vía telegrama colacionado durante el período de inasistencia, surge de autos otra prueba que cumplió la misma función. En este sentido se expresa: “...si bien es cierto que el empleador directo no intimó el reintegro del trabajador durante su inasistencia al trabajo se reveló otra prueba que cumplió la misma función".

Según analizaré a continuación, acertadamente el Tribunal consideró que el empleador cumplió con la función de demostrar su interés en la continuación de la relación de trabajo con el actor y lo constituyó en mora por incumplimiento de su obligación principal, que era precisamente trabajar o por lo menos estar a la orden de la empresa.

Lo trascendente e innovador de la Sentencia comentada consiste en la admisión de que puedan existir otros medios (en este caso un medio digital) hábiles para efectuar la referida intimación. Expresa en este sentido: "De allí que pueden existir otros medios de obtener el mismo propósito. Hoy por hoy la tecnología con presencia en la vida de las personas y también en la relación de trabajo con los connaturales limites a los derechos fundamentales del trabajador podría sustituir la clásica intimación por telegrama. Podría, en caso de que reportara al trabajador las mismas garantías de defensa y respeto a su intimidad y vida privada al tiempo de cumplir la misma función de constituirlo en mora demostrando el interés del empleador en la continuación de la relación de trabajo, que, ha sido el caso de autos como se verá".

En este sentido, el Tribunal entendió que las comunicaciones enviadas vía WhatsApp mediante las cuales la empresa convocó al trabajador, cumplieron la misma función que el telegrama colacionado, en virtud de que quedó demostrado que el trabajador recibió los mensajes en el número de teléfono indicado -y probado- por la empresa como propio del trabajador, no habiendo sido desconocido ni objetado este punto por el actor en el juicio.

A su vez, el empleador demostró que dichas comunicaciones fueron realizadas por la secretaria de recursos humanos de la empresa, desde su teléfono celular, lo cual fue 
reconocido y ratificado en audiencia por esta trabajadora. Este punto, también es de relevancia en el caso concreto, en virtud de que la demandada fue diligente y procuró reforzar el valor probatorio de la intimación realizada por medio digital.

\section{De la forma de aportación de los mensajes enviados vía whatsapp}

Otro elemento importante a destacar de la Sentencia, es la forma en que el demandado incorporó al proceso las comunicaciones mantenidas con el trabajador vía WhatsApp. Según se detalla, el empleador aportó un acta de constatación notarial con "foto de imágenes del aparato...", dicho de otro modo, capturas de pantalla de la aplicación WhatsApp efectuadas desde un teléfono celular del cual se indica su número e identificándose además, el número a donde se enviaron los mensajes.

Asimismo, la actuación notarial constata, las fechas de los mensajes e imágenes extraídas de dicha aplicación y también hace referencia a mensajes de audios que fueron escuchados por la escribana actuante e incorporados como prueba al proceso.

En la Sentencia, expresamente se hace alusión a la falta de oposición de la contraria respecto a las formalidades en las que fue aportada dicha prueba, así se manifiesta en reiteradas oportunidades: "... Este medio probatorio digital fue incorporado al proceso ante el ofertorio de la parte demandada y, primero, no recibió objeciones de la parte contraria en el aspecto formal" y luego reitera: "Y como se ha dicho, esta formalidad procesal no resultó cuestionada por el accionante".

Más allá de las diferentes posturas que existen sobre la forma de aportación en juicio de este tipo de probanzas -en las cuales no ahondaré en el presente trabajo por exceder el objeto del mismo- considero correcta la solución arribada por el Tribunal.

En efecto, como correctamente destaca ALMEIDA, “...las exigencias previstas en el art. 72.1 del CGP, parecerían resultar anacrónicas con los avances tecnológicos que se presentan en la

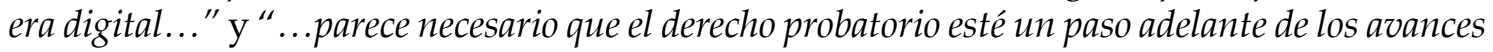
tecnológicos, y a la luz del principio de libertad de la prueba, se analice la posible admisibilidad de estas simples capturas, las que deberán ser consideradas con las debidas cautelas, en atención a la manipulación que pudieran sufrir estas comunicaciones"7.

En síntesis, se entiende que ha sido correcta la forma de aportación de la prueba por parte de la demandada y asimismo, correctas las consideraciones elaboradas por el Tribunal.

\section{El actor no desconoció el contenido de los mensajes de whatsapp}

Como se viene de decir, el actor tampoco formuló objeciones respecto al contenido material de los mensajes incorporados al proceso. Del acta de constatación notarial surge un número de teléfono celular, el cual la empresa empleadora lo identifica como perteneciente al actor, lo que no fue objetado por este.

7 Almeida, Rodrigo, LOS DESAFÍOS PROBATORIOS CON LOS QUE ACARREAN LOS MENSAJES DE INSTAGRAM Y DE WHATSAPP, en las XIX Jornadas Nacionales de Derecho Procesal en homenaje a Gonzalo Uriarte, FCU, año 2019, pág. 71. 
Por tanto, el trabajador no desconoció que el número al cual la secretaria de recursos humanos de la empresa envió los mensajes de WhatsApp, no fuera suyo. Tampoco el actor, expresó en el proceso no haber recibido los mensajes en su celular, ni desconoció que los audios que fueran reproducidos en audiencia, no hayan sido recibidos ni enviados por él.

Estos elementos resultan trascendentes en el caso de autos, en tanto, el no desconocimiento por parte del actor en los términos previstos por el art. 170 del CGP, derivan en la autenticación del documento privado aportado por su contraparte.

Lo expresado, pone de manifiesto que la convocatoria a trabajar efectuada por la empresa por este medio digital, con el objetivo de constituir en mora al trabajador, resultó idónea, en virtud que el empleado efectivamente tomó conocimiento de la intención de su empleador de continuar el vínculo laboral.

\section{La eventual relevancia del contrato de trabajo}

Las sentencias de ambas instancias no hacen referencia alguna al contrato de trabajo existente entre el trabajador y el empleador.

Sin perjuicio de ello, corresponde mencionar que al ingresar a trabajar a la empresa, el trabajador suscribió un contrato de trabajo pero en el mismo no se reguló ningún aspecto referido a la comunicación entre las partes.

Por tanto, el hecho que el contrato de trabajo no estableciera nada al respecto, abre a mí entender, un espectro de diferentes canales por medio de los cuales se podrían cursar las comunicaciones entre empleador y trabajador, tal como aconteció en el caso comentado.

\section{Inexistencia de incumplimiento y configuración de abonado del trabajo}

En el caso de autos, al igual que lo sostuvo la Sede en primera instancia, el Tribunal entendió que no se relevaron los incumplimientos alegados por el actor, y por tanto, su no presentación a trabajar careció de fundamentos: "De allí que ante el llamado al reintegro que puede interpretarse de los documentos digitales, la condición invocada por el trabajador carecía de sustento real".

En virtud de ello, habiendo el empleador intimado el reintegro al actor, y dado que los incumplimientos alegados por este carecieron de respaldo probatorio, el Tribunal consideró que se configuró una hipótesis de abandono del puesto de trabajo por parte del empleado: "En definitiva la finalización de la relación de trabajo puede entenderse que obedeció al abandono de trabajo y no al despido indirecto".

En definitiva, la empresa empleadora demostró en el proceso que la relación laboral con el actor finalizó por voluntad unilateral de este, habiendo constituido en mora al trabajador ante su ausencia injustificada al trabajo. Por tal razón y al no haber existido los incumplimientos alegados por el empleado, acertadamente el Tribunal entendió configurado el abandono del puesto de trabajo por parte del trabajador. 


\section{Conclusiones}

El avance y el desarrollo de la tecnología han generado grandes cambios en los medios de comunicación y en la forma de interactuar entre las personas.

En la actualidad, dicha interacción se da en gran medida a través de medios tecnológicos tales como el correo electrónico, la aplicación WhatsApp, redes sociales, entre otros.

En este escenario, las relaciones laborales no son ajenas a los cambios en los medios y formas de comunicación entre las personas. Así, durante el vínculo laboral entre el empleador y el empleado, se presentan un sinfín de situaciones en las cuales se utilizan vías de comunicación distintas a las tradicionales.

Por tal razón, uno de los grandes desafíos para la justicia en la actualidad, es conciliar la legislación existente con los nuevos medios de comunicación que a diario utilizamos.

En este sentido, el fallo analizado es trascendente en virtud de que integra el elenco de los primeros pronunciamientos de la justicia laboral a favor de la aceptación de elementos probatorios provenientes de la aplicación WhatsApp, con la finalidad de acreditar situaciones tales como la renuncia o la intimación al reintegro de un trabajador, considerando que la normativa no establece requisitos de solemnidad con respecto a dichos actos.

\section{Bibliografía}

Barbagelata, Héctor Hugo, Derecho del Trabajo, T. I., FCU, año 1992.

Almeida, Rodrigo, Los desafíos probatorios con los que acarrean los mensajes de Instagram y de Whatsapp, en las XIX Jornadas Nacionales de Derecho Procesal en homenaje a Gonzalo Uriarte, FCU, año 2019.

Uruguay, Juzgado Letrado de Trabajo $14^{\circ}$, Sentencia $N^{\circ} 111$, de fecha 19.10.2004, AJL 2004, Caso 9.

Uruguay, Tribunal de Apelaciones del Trabajo de $1^{\circ} \mathrm{T}$, Sentencia $\mathrm{N}^{\circ} 223$, de fecha 25.5.2004, AJL 2004, Caso 10.

Uruguay, Tribunal de Apelaciones del Trabajo $3^{\circ}$ T, Sentencia $N^{\circ} 101 / 2007$, BJNP.

Uruguay, Tribunal de Apelaciones del Trabajo $3^{\circ} \mathrm{T}$, Sentencia $\mathrm{N}^{\circ}$ 526/2010, BJNP.

Uruguay, Tribunal de Apelaciones del Trabajo del Trabajo $2^{\circ} \mathrm{T}$, Sentencia SEF - 0013000092/2014, BJNP.Uruguay, Tribunal de Apelaciones del Trabajo de $3^{\circ} \mathrm{T}$, Sentencia SEF - 0014-000035, de fecha 13.5.2015, AJL 2015 Caso 7. 